\title{
The impact of drawing on the biogenic amines content in meat of pithed pheasant
}

\author{
Zdeňka Hutařová1, Vladimír Večerek ${ }^{1}$, Petr Maršálek ${ }^{1}$, Gabriela Bořilová2 \\ Iva Steinhauserová ${ }^{2}$
}

\begin{abstract}
${ }^{1}$ University of Veterinary and Pharmaceutical Sciences Brno, Faculty of Veterinary Hygiene and Ecology, Department of Veterinary Public Health and Animal Welfare, ${ }^{2}$ Department of Meat Hygiene and Technology, Brno, Czech Republic
\end{abstract}

Received April 3, 2013

Accepted September 29, 2013

\begin{abstract}
With the increasing popularity of game meat, greater emphasis is being placed on ensuring high hygienic quality of this food. Biogenic amines are among possible indicators of the hygienic quality of meat. The aim of this study was to monitor biogenic amine concentrations in the muscle tissues of pheasants $(n=20)$ killed by pithing and treated by drawing (guts are removed from the body cavity through the cloaca using a specially fashioned hook). The pheasants' bodies were stored hanged by the neck for 21 days at $\pm 7^{\circ} \mathrm{C}$. Breast and thigh muscle samples were collected at weekly intervals (day 1, 7, 14 and 21 of storage). Biogenic amines (putrescine, cadaverine, tyramine, histamine, tryptamine and phenylethylamine) were analysed by reverse phase liquid chromatography and detected by tandem mass spectrometry. In breast muscle, the most evident change was noted in the concentration of cadaverine $(0.026$ and $1.070 \mathrm{mg} / \mathrm{kg}$ for storage day 1 and 21 , respectively) and tyramine ( 0.001 and $0.958 \mathrm{mg} / \mathrm{kg}$ for storage day 1 and 21 , respectively). Throughout the storage period, the concentration of $5 \mathrm{mg} / \mathrm{kg}$ (indicating a loss of high hygienic quality of meat) was not exceeded by any of the assessed biogenic amines. In thigh muscle, the concentration indicating high hygienic quality of meat was exceed after 14 days of storage in the case of cadaverine, tyramine and putrescine (at the end of storage their concentrations were $9.058,10.708$ and $3.345 \mathrm{mg} / \mathrm{kg}$, respectively). Hygienic quality of thigh muscle decreased faster compared to breast muscle. This study brings new information about the content of biogenic amines in the meat of pithed pheasants treated by drawing.
\end{abstract}

Cadaverine, feathered game, hygienic quality, post-mortem treatment, putrescine

Game meat is becoming an increasingly popular food (Atanassova et al. 2008). In feathered game production, raising pheasants on farms specifically for meat production is becoming more wide-spread (Hofbauer et al. 2010; Golze 2011). With the consumers' increasing interest in game meat, greater emphasis is being placed on ensuring high hygienic quality of meat. Hygienic quality is closely connected with the manner in which carcasses are processed and subsequently handled (Atanassova et al. 2008). One of the possible ways of killing farm-raised pheasants is to sever their spinal cord between the skull base and the first cervical vertebra (referred to as pithing). Feathered game carcasses may be processed in various ways. One possibility is the so-called drawing, when the guts are removed from the body cavity through the cloaca using a specially fashioned hook. This process satisfies the requirement of a rapid removal of the digestive tract from the body cavity but, at the same time, poses a risk of body cavity contamination in the case of gut rupture. Opinions on the use of this kind of processing vary, and the recommended processing of feathered game carcasses is to open the body cavity and remove the internal organs from it (Winkelmayer et al. 2004). Nevertheless, drawing is still used in practice. Scientific information on the effects of pheasant carcass processing by drawing on biogenic amine formation during carcass storage has not been published yet. Changes in biogenic amine concentrations during storage of pheasants killed by pithing and then either

Address for correspondence:

MVDr. Zdeňka Hutařová

Department of Veterinary Public Health and Animal Welfare

Faculty of Veterinary Hygiene and Technology

University of Veterinary and Pharmaceutical Sciences Brno

Palackého tř. 1/3, 61242 Brno, Czech Republic 
eviscerated or left without further processing were investigated in the studies of Hutarova et al. (2013a,b).

Biogenic amines and their formation in foods are associated with a degree of microbial contamination (Ruiz-Capillas and Jimenez-Colmendo 2004), and are considered indicators of hygienic quality of various foods including meat (Favaro et al. 2007; Boka et al. 2012).

The aim of the study was to asses the suitability of drawing for the processing of farmraised pheasants killed by pithing in terms of ensuring high hygienic quality of meat of common pheasants stored in feathers.

\section{Materials and Methods}

The research was managed according to the experimental project authorized by the Ministry of Agriculture of the Czech Republic and the Ethics Committee of the University of Veterinary and Pharmaceutical Sciences Brno. A total of 20 pheasants (males, mean weight $1.13 \mathrm{~kg} \pm 152 \mathrm{~g}$ ) raised at the school farm in Nový Jičín (owned by the University of Veterinary and Pharmaceutical Sciences in Brno) were used in our study. The pheasants were killed by pithing (severing the spinal cord). The carcasses of pheasants were consequently treated by drawing, i.e. removing the intestines from the body cavity through the cloaca using a specially fashioned hook. Then, the carcasses were placed into coolers pre-set at the temperature of $7^{\circ} \mathrm{C}$ performing the highest possible temperature for storage of small wild game carcasses. Whole breast and thigh muscles were taken from 5 pheasant carcasses at weekly intervals starting on day 1 after the birds were killed.

The total amount of $0.5 \mathrm{~g}$ of homogenised muscle tissue from each bird was used for biogenic amines assessment. Samples were employed by one-step extraction using $5 \%$ mixture of trichloracetic acid in water followed by clean-up step using a $0.45 \mu \mathrm{m}$ syringe filter. Biogenic amines were separated from extract by reverse phase liquid chromatography using $\mathrm{C}_{18}$ column $(2.1 \mathrm{~mm} \times 50 \mathrm{~mm}, 1.9 \mu \mathrm{m}$; Thermo, San Jose, CA, USA) and detected by tandem mass spectrometry using a heated electro spray-ionization in a positive ion mode. Thermo Scientific UHPLC Accela 1250 system was connected to a Thermo Scientific TSQ Quantum Access MAX Triple Quadrupole Instrument (Thermo, San Jose, CA, USA). Evaluation of the results was performed by assessing the changes of concentration of selected biogenic amine (putrescine, cadaverine, tyramine, histamine, tryptamine and phenylethylamine) in muscle samples.

The significance of differences in the selected biogenic amine concentrations between individual sampling and between breast and thigh muscle samples was evaluated by the Kruskal-Wallis test in the statistical analysis package UNISTAT 5.6. The $P$ value $<0.05$ was considered as significant.

\section{Results}

Changes in biogenic amine concentrations in the breast muscle of drawn pheasants killed by pithing are shown in Table 1 .

Major changes (concentration changes in excess of $0.5 \mathrm{mg} / \mathrm{kg}$ ) between days 1 and 21 were recorded in cadaverine and tyramine concentrations with the main increase after storage day 14 . However, the mean values of these changes were non-significant

Table 1. Concentrations of selected biogenic amines in breast muscle of drawn pheasants killed by pithing stored at $\pm 7^{\circ} \mathrm{C}$.

\begin{tabular}{lcccc}
\hline \multirow{2}{*}{ Biogenic amine } & \multicolumn{4}{c}{ Storage day } \\
\cline { 2 - 5 } & $0.009 \pm 0.000$ & $0.009 \pm 0.000$ & $0.009 \pm 0.000$ & $0.009 \pm 0.000$ \\
\hline Putrescine & $0.026 \pm 0.000$ & $0.026 \pm 0.000$ & $0.026 \pm 0.000$ & $1.070 \pm 2.334$ \\
Cadaverine & $0.014 \pm 0.000$ & $0.018 \pm 0.010$ & $0.014 \pm 0.000$ & $0.014 \pm 0.000$ \\
Histamine & $0.001 \pm 0.000$ & $0.001 \pm 0.000$ & $0.168 \pm 0.373$ & $0.958 \pm 0.950$ \\
Tyramine & $0.001 \pm 0.000$ & $0.001 \pm 0.000$ & $0.001 \pm 0.000$ & $0.004 \pm 0.006$ \\
Phenylethylamine & $0.002 \pm 0.000$ & $0.002 \pm 0.000$ & $0.002 \pm 0.000$ & $0.042 \pm 0.091$ \\
Tryptamine & & & & 14 \\
\hline
\end{tabular}

Data presented as mean \pm standard deviation; in each term 5 samples were assessed 
( $P=0.9507$ and $P=0.3322$ for cadaverine and tyramine, respectively). From the hygienic quality point of view, these changes indicate that biogenic amine concentrations in some pheasants may exceed limits for meat of high hygienic quality. Changes in concentration of other biogenic amines (putrescine, histamine, phenylethylamine and tryptamine) in breast muscle were non-significant. Overall changes in biogenic amine concentrations in breast muscles were small and during the whole storage period did not reach the limit value $(5 \mathrm{mg} / \mathrm{kg})$ for meat of high hygienic quality.

Changes in biogenic amine concentrations in the thigh muscle of drawn pheasants killed by pithing are shown in Table 2 .

Table 2. Concentrations of selected biogenic amines in thigh muscle of drawn pheasants killed by pithing stored at $\pm 7^{\circ} \mathrm{C}$.

\begin{tabular}{lcccc}
\hline \multirow{2}{*}{ Biogenic amine } & \multicolumn{4}{c}{ Storage day } \\
\cline { 2 - 5 } & 1 & 7 & 14 & 21 \\
\hline Putrescine & $1.531 \pm 0.336$ & $0.968 \pm 0.439$ & $1.411 \pm 0.292$ & $3.345 \pm 3.621$ \\
Cadaverine & $0.026 \pm 0.000$ & $0.026 \pm 0.000$ & $1.124 \pm 2.454$ & $9.058 \pm 12.405$ \\
Histamine & $0.503 \pm 0.155$ & $0.237 \pm 0.058$ & $0.585 \pm 0.212$ & $0.845 \pm 0.481$ \\
Tyramine & $0.001 \pm 0.000$ & $0.001 \pm 0.000$ & $0.639 \pm 0.380$ & $10.708 \pm 10.261$ \\
Phenylethylamine & $0.001 \pm 0.000$ & $0.001 \pm 0.000$ & $0.004 \pm 0.007$ & $0.001 \pm 0.000$ \\
Tryptamine & $0.002 \pm 0.000$ & $0.002 \pm 0.000$ & $0.002 \pm 0.000$ & $0.065 \pm 0.141$ \\
\hline
\end{tabular}

Data presented as mean \pm standard deviation; in each term 5 samples were assessed

The most apparent changes in biogenic amine concentrations (changes in excess of $0.5 \mathrm{mg} / \mathrm{kg}$ ) in the thigh muscle of drawn pheasants between storage days 1 and 21 were recorded in putrescine, cadaverine and tyramine. However, the increase in mean concentrations of these biogenic amines during storage was non-significant $(P=0.8536$, $P=0.3615$ and $P=0.0504$ for putrescine, cadaverine and tyramine, respectively). In some pheasants, concentrations of these biogenic amines reached levels characteristic for meat of low hygienic quality with initial signs of spoilage. Changes in concentrations (less than 0.5 $\mathrm{mg} / \mathrm{kg}$ ) of the remaining biogenic amines (histamine, phenylethylamine and tryptamine) were non-significant during the whole storage period. Changes in putrescine concentration were apparent during the whole storage period. The concentrations of cadaverin and tyramine in thigh muscle increased after storage day 14. Overall concentration of biogenic amines in thigh muscle exceeded the limit value $(5 \mathrm{mg} / \mathrm{kg})$ for high hygienic quality of meat after 14 days of storage.

It follows from our results that the intensity and speed of biogenic amine formation differs between breast and thigh muscle. The significant difference between breast and thigh muscles was found on all sampling days in putrescine concentrations $(P=0.0090$ for all sampling days).

\section{Discussion}

Measuring of biogenic amine concentrations in pheasants killed by pithing and subsequently drawn through the cloaca and stored at $\pm 7^{\circ} \mathrm{C}$ is important for the evaluation of the effects of processing and storage temperature on the hygienic quality of pheasant meat. The effect of temperature on the formation of biogenic amines was described by Naila et al. (2011). Paulsen et al. (2008) monitored the formation of biogenic amines in muscle tissues of pheasants stored at $0{ }^{\circ} \mathrm{C}$ and $4{ }^{\circ} \mathrm{C}$ for 14 days. Biogenic amine concentration of $1 \mathrm{mg} / \mathrm{kg}$ was not exceeded in $90 \%$ of samples. Compared to those results, concentrations 
of biogenic amines determined in our study were higher (especially in thigh muscle). This fact could be due to a higher storage temperature used in our study.

The suitability of processing feathered game by drawing through the cloaca for maintaining the hygienic quality of meat can be assessed by comparing our results with the findings in eviscerated and uneviscerated pheasants stored at the same temperature $7{ }^{\circ} \mathrm{C}$ (Hutarova et al. 2013a,b). Hardly any changes in concentration of biogenic amines were observed in muscle tissues of uneviscerated pheasants (Hutarova et al. 2013b) whereas higher concentrations of biogenic amines were recorded in eviscerated pheasants (Hutarova et al. 2013a). In terms of biogenic amines, the results show that the generally recommended mode of treatment of feathered game evisceration (Winkelmayer et al. 2004 ) is no more appropriate than drawing. In our study, we found that cadaverine, tyramine and putrescine had the highest informative value with respect to the hygienic quality of pheasant meat. The same results were reported by Hutarova et al. (2013b). HernandezJover et al. (1996) determined cadaverine, putrescine, histamine and tyramine as the major indicators of hygienic quality of pork meat. In our study, no major changes in histamine concentrations occurred in either breast or thigh muscles. An increase in concentrations of histamine of uneviscerated pheasants stored at the temperature of $15^{\circ} \mathrm{C}$ was described by Hutarova et al. (2013b). The results may lead us to the conclusion that histamine begins to form in pheasant meat when exposed to higher storage temperatures.

In our study, marked changes exceeding the hygienic quality limits were observed after 14 days of storage in tyramine and cadaverine. The changes in concentration of amines in pheasants killed by pithing and drawn through the cloaca occur later than in eviscerated pheasants where more marked changes in concentration of biogenic amines were observed already after 7 days of storage (Hutarova et al. 2013a). Standarova et al. (2012) also reported changes in concentration of biogenic amines in thigh muscle of uneviscerated pheasants during the second week of storage at refrigeration temperatures. In our study, changes in concentration of cadaverine and tyramine in breast muscle did not reach amounts considered as limits for change in the hygienic quality of meat. Hutarova et al. (2013b) reported results similar to those in our study. Pheasants drawn through the cloaca in our study showed lower concentrations of biogenic amines after 14 days of storage compared to eviscerated pheasants in the study conducted by Hutarova et al. (2013b).

It also follows from our results that thigh muscle of pheasant drawn through the cloaca contained higher concentrations of biogenic amines than breast muscle. The same results were found in eviscerated pheasants stored at $7{ }^{\circ} \mathrm{C}$ (Hutarova et al. 2013a) and in uneviscerated pheasants stored at $15{ }^{\circ} \mathrm{C}$ (Hutarova et al. 2013b). Contrary findings were reported by Standarova et al. (2012) and Silva and Gloria (2002) in their studies with pheasant and poultry muscle tissues, respectively. The differences in the results may have been caused by the type of carcass hanging during storage or by different muscle composition compared to poultry meat.

\section{Acknowledgement}

This study was supported by the IGA 93/2011/FVHE project.

\section{References}

Atanassova V, Apelt J, Reich F, Klein G 2008: Microbiological quality of freshly shot game in Germany. Meat Sci 78: 414-419

Balamatsia CC, Paleologos EK, Kontominas MG, Sayvaidis IN 2006: Correlation between microbial flora, sensory changes and biogenic amines formation in fresh chicken meat stored aerobically or under modified atmosphere packing at $4{ }^{\circ} \mathrm{C}$ : possible role of biogenic amines as spoilage indicators. Anton Leeuw Int $\mathrm{J} G$ 89: 9-17

Boka B, Adanyi N, Virag D, Sebela M, Kiss A 2012: Spoilage detection with biogenic amine biosensor of different enzyme electrodes. Electroanal 24: 181-186 
Duflos G 2009: Histamine risk in fishery products. Bulletin de l'Academie Veterinaire de France 162: 241-246

Favaro G, Pastore P, Saccani G, Cavalli S 2007: Determination of biogenic amines in fresh and processed meat by ion chromatography and integrated pulsed amperometric detection on $\mathrm{Au}$ electrode. Food Chem 105: $1652-1658$

Halasz A, Barath A, Simon-Sarkadi L, Holzapfel W 1994: Biogenic amines and their production by microorganisms in food. Trends Food Sci Tech 5: 42-49

Hernandez-Jover T, Izquierdo-Pulido M, Veciana-Nogues MT, Vidal-Carou MC 1996: Biogenic amine sources in cooked cured shoulder pork. J Agric Food Chem 44: 3097-3101

Hofbauer P, Smulders FJM, Vodnansky M, Paulsen P, El-Ghareeb WR 2010: A note on meat quality traits of pheasant (Phasianus colchicus). Eur J Wildl Res 56: 809-813

Hutarova Z, Vecerek V, Marsalek P., Steinhauserova I., Borilova G 2013a: Changes in biogenic amine concetrations in meat of eviscerated pheasants (Phasianus colchicus) during storage at $7^{\circ} \mathrm{C}$. Acta Vet Brno 82: 175-180

Hutarova Z, Vecerek V, Steinhauserova I, Marsalek P, Borilova G 2013b: Effects of storage temperature on biogenic amine concentrations in meat of uneviscerated pheasants (Phasianus colchicus). Acta Vet Brno 82: $61-65$

Naila A, Flint S, Fletcher G, Bremer P, Meerdink G 2010: Control of biogenic amines in food - existing and emerging approaches. J Food Sci 75: 139-150

Paulsen P, Nagy J, Popelka P, Ledecky V, Marcincak S, Pipova M, Smudlers FJM, Hofbauer P, Lazar P, Dicakova Z 2008: Influence of storage conditions and shotshell wounding on the hygienic condition of hunted, uneviscerated Pheasant (Phasianus colchicus). Poutry Sci 87: 191-195

Prester L, Macan J, Varnai VM, Orct T, Vukusic J, Kipcic D 2009: Endotoxin and biogenic amine levels in Atlantic mackerel (Scomber scombrus), sardine (Sardina pilchardus) and Mediterranean hake (Merluccius merluciccius) stored at 22 degrees C. Food Addit Contam. Part A Chem Anal Control Expo Risk Assess 26: 355-362

Ruiz-Capillas C, Jimenez-Colmenero F 2004: Biogenic amines in meat and meat products. Crit Rev Sci Nutr 44: 489-499

Standarova E, Vorlova L, Gallas L 2012: Distribution of biogenic amines and polyamines in the pheasant meat (in Czech). Maso 1: 51-54

Winkelmayer R, Lebersorger P, Zedka HF 2004: Meat hygiene (in German). Zentralstelle Üsterr. Landesjagdverbände, Wien, 83 p. 